tory to treatment, thus introducing a selection bias. To address this concern, we reanalyzed our data to determine the outcomes of the 62 excluded patients. If the excluded patients were treatment failures, one would expect a higher mortality rate than in the analyzed group. However, the in-hospital mortality for the excluded patients was $60 \%$ (37/62), which was slightly lower than the population included in the study (68\%), arguing against therapeutic failure in the patients with incomplete documentation.

Brain herniation is a medical emergency analogous to cardiopulmonary arrest and delaying treatment in order to obtain central venous access is unacceptable. Thus, $23.4 \%$ may only be used as a first-line hyperosmolar agent in patients with a preexisting central venous catheter. In others, a peripherally compatible hyperosmolar agent such as mannitol should be given initially, until central access has been established. In our Neurosciences Critical Care Unit this has rarely been an issue, since a high proportion of patients who experience herniation already have central venous access.

Robert D. Stevens, Matthew A. Koenig,

Baltimore, MD

Disclosure: The authors report no disclosures.

Copyright (C) 2009 by AAN Enterprises, Inc.
1. Koenig MA, Bryan M, Lewin JL 3rd, et al. Reversal of transtentorial herniation with hypertonic saline. Neurology 2008;70:1023-1029.

2. Videen TO, Zazulia AR, Manno EM. Mannitol bolus preferentially shrinks noninfarcted brain in patients with ischemic stroke. Neurology 2001:57:2120-2122.

3. Ritter A, Muizelaar J, Barnes T, et al. Brain stem blood flow, pupillary response, and outcome in patients with severe head injuries. Neurosurgery 1999;44:941-948.

4. Wijdicks EFM. Acute brainstem displacement without uncal herniation and posterior cerebral artery injury. J Neurosurg Neurol Psychiatry 2008 (in press).

5. Tseng MY, Al-Rawi PG, Czosnyka M, et al. Enhancement of cerebral blood flow using systemic hypertonic saline therapy improves outcome with poor-grade spontaneous subarachnoid hemorrhage. J Neurosurg 2007: $274-284$

6. Reich JB, Sierra J, Camp W, Zanzonico P, Deck MD, Plum F. Magnetic resonance imaging measurements and clinical changes accompanying transtentorial and foramen magnum brain herniation. Ann Neurol 1993;33:159170.

7. Ropper AH. Lateral displacement of the brain and level of consciousness in patients with an acute hemispheral mass. N Engl J Med 1986;314:953-958.

8. Meyer A. Herniation of the brain. Arch Neurol Psychiatry 1920;4:387-400.

9. Posner JB, Plum F. Plum and Posner's Diagnosis of Stupor and Coma. 4th ed. New York: Oxford University Press; 2007.

\title{
CORRECTION
}

\section{Lamotrigine extended-release as adjunctive therapy for partial seizures}

In the article "Lamotrigine extended-release as adjunctive therapy for partial seizures" by D.K. Naritoku et al. (Neurology ${ }^{\circledR}$ 2007;69:1610-1618), as a result of changes to the database from audits conducted across all participating study sites, some of the data reported in the manuscript have changed slightly. These audits were conducted by the study sponsor, GlaxoSmithKline, in preparation for response to the FDA approvable letter for the Lamictal XR New Drug Application. The outcome of the audits did not change the overall conclusions of the study, but did lead to small changes in some of the data in the manuscript. The new data have replaced the previous numbers published in the abstract, now in brackets:

\section{ABSTRACT}

Objective: To evaluate the efficacy and tolerability of once-daily adjunctive lamotrigine extended-release (XR) for partial seizures in epilepsy.

Methods: Patients more than 12 years old diagnosed with epilepsy with partial seizures and taking one to two baseline antiepileptic drugs were randomized to adjunctive once-daily lamotrigine XR or placebo in a double-blind, parallel-group trial. The study comprised a baseline phase, a 7 -week double-blind escalation phase, and a 12-week double-blind maintenance phase during which doses of study medication and concomitant antiepileptic drugs were maintained.

Results: Of the 243 randomized patients, 239 (118 lamotrigine XR, 121 placebo) entered the escalation phase and received study medication. Lamotrigine XR was more effective than placebo with respect to median percent reduction from baseline in weekly partial seizure frequency (primary endpoint—entire 19-week treatment phase: $46.6 \%$ [was $46.1 \%$ ] vs $\underline{24.5} \%$ [was $24.2 \%$ ], $p=\underline{0.0001}$ [was 0.0004 ] via Wilcoxon test; escalation phase: $29.8 \%$ [was $28.0 \%$ ] vs $\underline{15.6 \%}$ [was $16.3 \%$ ], $p=\underline{0.027}$ [was 0.028 ]; maintenance phase: $58.4 \%$ [was $58.0 \%$ ] vs $26.8 \%$ [was $26.7 \%$ ], $p<0.0001$ ). The percentage of patients with $\geq 50 \%$ reduction in partial seizure frequency $(\underline{44.0 \%}$ [was $42.2 \%$ ] vs $\underline{20.8} \%$ [was $24.2 \%$ ], $p=\underline{0.0002}$ [was 0.0037 ]) and time to $\geq 50 \%$ reduction in partial seizure frequency $(p=$ 0.0001) (was 0.0007) also favored lamotrigine XR over placebo. A similar pattern of results was observed for secondarily generalized seizures. The most common adverse events were headache (lamotrigine XR $\underline{16 \%}$ [was 17\%], placebo $\underline{18 \%}$ [was 15\%]) and dizziness (lamotrigine XR 19\% [was 18\%], placebo 5\%). Differences between lamotrigine XR and placebo on health outcomes measures were not significant.

Conclusions: Once-daily adjunctive lamotrigine extended-release compared with placebo effectively reduced partial seizure frequency and was well tolerated in this double-blind study. Results support the clinical utility of this new once-daily formulation. 


\section{Neurology}

\section{Lamotrigine extended-release as adjunctive therapy for partial seizures Neurology 2009;72;201 \\ DOI 10.1212/01.wnl.0000344239.19790.54}

This information is current as of January 12, 2009

\section{Updated Information \&}

Services

Permissions \& Licensing

Reprints including high resolution figures, can be found at: http://n.neurology.org/content/72/2/201.full

Information about reproducing this article in parts (figures,tables) or in its entirety can be found online at:

http://www.neurology.org/about/about_the_journal\#permissions

Information about ordering reprints can be found online:

http://n.neurology.org/subscribers/advertise

Neurology ${ }^{\circledR}$ is the official journal of the American Academy of Neurology. Published continuously since 1951, it is now a weekly with 48 issues per year. Copyright. All rights reserved. Print ISSN: 0028-3878. Online ISSN: 1526-632X.

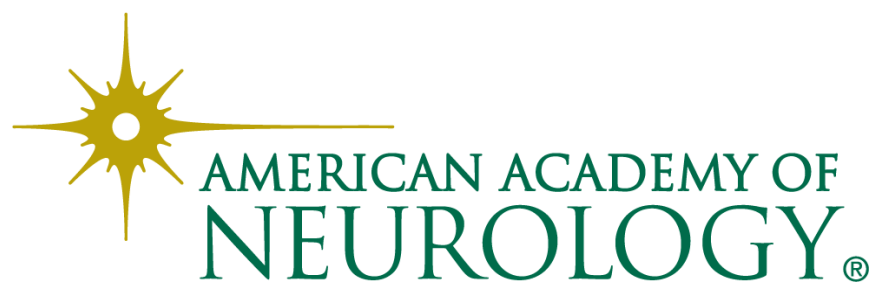

